\title{
LA POLÍTICA DE ESTADOS UNIDOS CONTRA EL NARCOTRÁFICO Y SU IMPACTO EN AMÉRICA LATINA
}

\author{
Fernando Bustamante
}

\begin{abstract}
A partir del inicio de la administración Reagan, el problema del consumo y tráfico de drogas ilegales en los Estados Unidos ha ido concitando una creciente preocupación y alarma en la opinión pública de dicho país.
\end{abstract}

Al mismo tiempo, en los últimos años han ido surgiendo una serie de voces ligadas al gobierno de Washington y a las agencias de orden público, que denuncian los lazos que unen a ciertos movimientos guerrilleros en distintas partes del mundo con las bandas de narcotraficantes. ${ }^{1}$

De esta forma ha ido tomando cuerpo el concepto de "narcoterrorismo"; el cual tiende a afirmar que estamos en presencia de un fenómeno nuevo: un movimiento político que une los objetivos de ambas actividades, o sea, la subversión política y tráfico de estupefacientes, así como las estructuras operacionales de ambas actividades. El "narcoterrorismo" se presenta entonces como una gran conspiración político-delictual encaminada a minar y destruir las bases de la sociedad norteamericana. ${ }^{2}$ De esta idea se desprenden una serie de políticas y actitudes norteamericanas hacia el problema en Latinoamérica y hacia sus países y gobiernos, que se caracterizan por su

[1]La vinculación iđeológica que se hace entre narcotráfico y terrorismo puede verse expresada muy claramente en: Drugs and Terrorism 1984, Audiencia del Subcomité sobre Alcoholismo y Drogadicción del Comité de Asuntos Laborales y Recursos Humanos del Senado de los Estados Unidos, agosto 2, 1984.

[2]Ver actas de las citadas audiencias. Senadora Paula Hawkings, Presidente de la Subcomisión, se apoya en la autoridad de Michael Ledeen del Centro de Estudios Estratégicos de la Universidad de Georgetown, grupo muy influyente en la administración republicana del Presidente Reagan. También deben enfatizarse las declaraciones de William van Raab, Comisionado del Servicio Nacional de Aduanas de Estados Unidos quien testifica señalando las instancias y formas de coorđinación operativa entre países de Europa Oriental, Cuba, movimientos terroristas de izquierda y los narcotraficantes. Ver también testimonio de Francis Mullen, Director de la Drug Enforcement Administration (DEA) y Clyde Taylor, Secretario de Estado Interino para Asuntos Relativos a Tráfico Internacional de Narcóticos. 
Fernando Bustamante / La política de Estados Unidos contra el ...

énfasis en la ayuda policial e incluso militar y que tiende a "fusionar" lo político/militar con lo policíaco y a convertir los problemas de bandolerismo, guerrilla, delincuencia y resistencia campesina tradicional al control del Estado central, en problemas de seguridad nacional de los Estados Unidos. ${ }^{3}$ De esta manera, el discurso sobre "narcoterrorismo" hace del remoto campesino peruano, cultivador ancestral de coca, parte de un problema de seguridad interna y de supervivencia del sistema político estadounidense. En esta imagen el temor al comunismo se fusiona con los miedos ancestrales al "indígena", al "otro" de tez morena y a los peligros de salud pública que la "epidemia" de la droga insinúa sobre una sociedad tan fuertemente obsesionada con la higiene, el cuerpo y la medicina como es la norteamericana. ${ }^{4}$ Así, subversión, enfermedad y "otredad" antropológica se unen en un poderoso racimo simbólico que cataliza una vigorosa reacción defensiva y la búsqueda de políticas hacia América Latina que revisten simultáneamente características de lucha antidelictual, anti-subversiva, cultural y epidemológica, y hace de sus agentes un sujeto sincrético que combina al policía, al soldado, al misionero-educador y al médico salubrista.

En este trabajo no se pretende dilucidar cuán reales son las percepciones norteamericanas sobre esta amenaza, cuán fundados sus temores, o cuán serio el problema de las drogas, tanto desde la perspectiva individual como de la social. No se pretende aquí calibrar la amenaza, su naturaleza y sus consecuencias. Lo que se pretende hacer es describir e interpretar el sentido de las percepciones y de la construcción que los estadounidenses hacen del problema. Se trata asimismo de entender los problemas que la aplicación de esa política enfrenta para operar eficazmente en un contexto, como el latinoamericano, donde existen una pluralidad de actores que no comparten esas percepciones, ni están socializados en una cultura política como la norteamericana, en la cual hallan pleno sentido las construcciones simbólicas que desembocan en la poderosamente cargada noción de "narcoterrorismo". Para poder hacer

\footnotetext{
[3] Ver testimonio de Francis Mullen, ibid.

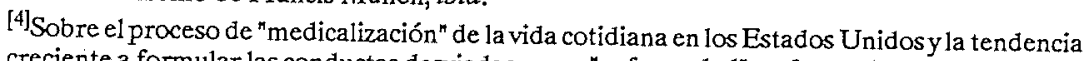
creciente a formular las conductas desviadas como "enfermedad" o efectos de ella, ver. Robert Crawford, Healthism and the Medicalization of Everyday Life: An Evaluation of Self-Help Holistic Health and the New Health Consciousness, (Chicago: University of Illinois, 1979).
} 
esto, se deberá. necesariamente mostrar cómo se ve tal conexión desde la perspectiva y la realidad de los actores locales, inmersos en problemáticas muy diferentes a aquellas en las cuales florecen las preocupaciones norteamericanas.

De esta forma podremos entender los resultados concretos de la política norteamericana en este campo y las posibles vías de evolución de este conflictivo ámbito de las relaciones entre Washington y sus vecinos hemisféricos.

\section{La percepción norteamericana del problema de la droga}

La percepción norteamericana con respecto a las drogas sufrió a partir de fines de la década de los 60 un vuelco muy marcado. Durante la década de los años 60 y principios de los 70 había ganado terreno una actitud relativamente tolerante con respecto al uso de estas sustancias. Incluso, ellas llegaron a simbolizar las aspiraciones y posturas de grupos que se planteaban polémicamente frente a la cultura predominante en su país. La tolerancia al uso de drogas sicotrópicas fue vista como una forma más de combatir el puritanismo cultural y los hábitos normativos y represivos de lo físico/afectivo que el espíritu racionalista y productivista del capitalismo "protestante" imponía a la población. ${ }^{5}$ De este modo la droga adquirió un status de signo de un conjunto de actitudes contestatarias de ciertas contra-élites vanguardistas.

A fines de la década pasada, el reflujo de la contra-cultura de los años 60 dejó la vía libre para que en este terreno, como en otros, los valores y actitudes tradicionales retornaran con renovado brío. Asimismo, la difusión del uso de las drogas alcanzó a muchos estratos en los cuales éste no tenía el valor de búsqueda, actualización o manifestación política que ciertas minorías ilustradas pretendían darle. Su uso en diversos grupos revistió crecientemente características de "vicio social", con efectos disolventes muy fuertes en las comunidades urbanas más afectadas. ${ }^{6}$ Este uso masivo consuetudi-

\footnotetext{
[5]Ver James Reichley, Religion in American Public Life, (Washington, D.C.: The Brookins Institution, 1985); Ray Billington, The Protestant Crusade 1800-1860: a Study in the Origins of American Nativism, (New York: 1938); Barxy Colman "Some Roots of American Nativism", Oregon Histarical Quarterly, Vol. 75, junio 1974.

[6]Ver Donald Louria, "The Future of the Drug Scene", The Futurist, 12,3, junio 1978. Ver Handbook on Drug Abuse, (Washington, D.C.: National Institute on Drug Abuse, 1979); "Cocaine: a 30 billion U. S. Habit", Time Magazine, julio 6, 1981.
} 
Fernando Bustamante/La política de Estados Unidos contra el ...

nario y anti-social hizo cundir la alarma y movilizó los modelos y representaciones colectivas tradicionales que la simbología del vicio y la enfermedad han gatillado secularmente en las sociedades puritanas.

Se hizo evidente que era necesario una sucesiva y renovada cruzada civilizadora y normativizadora al estilo de las tradicionales luchas anti-alcohólicas, anti-sexuales y anti-festivas, que marcaron buena parte de los conflictos culturales en los Estados Unidos del siglo XIX y principios del actual. ${ }^{7}$

La ilegalidad de la economía de la droga había conducido sin embargo, a una mucha mayor criminalización relativa de la organización de su distribución y consumo. Sólo en la época del prohibicionismo de los años 20 puede hallarse un comparable florecimiento de verdaderas empresas transnacionales del crimen, dedicadas a realizar las fabulosas ganancias que producía una demanda creciente e insaciable de sustancias sicotrópicas.

La criminalización creciente y concomitante de la droga hizo fácil para el público norteamericano concluir que la drogadicción era fruto de la promoción del vicio realizada por organizaciones delictuales. Aunque sin duda tal promoción existía, es dudoso que el origen histórico-causal de la difusión de los hábitos de consumo de drogas se deba primordialmente a sus actividades. Probablemente se trata de una conjunción de factores biológicos, sico-sociales, culturales y ambientales. ${ }^{8}$ Pero sea como sea, el público norteamericano tendió a sentir que la creciente drogadicción era ante todo resultado de una conspiración oculta de elementos criminales para destruir por dentro la sociedad. ${ }^{9}$ Esta imagen movilizó poderosos temores incons-

[7]Billington, op. cit, John Schneider, "Riot and Reaction in St. Louis 1854-56", Missouri Historical Reviews, vol, 68, enero 1974. Gustavus Myers, en: Henry Christman (ed.) History of Bigoty in the United States, (New York: 1960).

[8]Ver "Beating the Drug Devil", South, junio 1986. Donde se presenta un intento de ligar la etiología de la drogradicción al proceso de urbanización y de destrucción de las pautas tradicionales de socialización y de vida cultural. Estos factores operarían a través de su impacto sico-social sobre los individuos y grupos desarraigados. En esta interpretación las drogas son un sub-producto del proceso de modernización.

[9] Amplia caja de resonancia de tales opiniones pueden hallarse en la Audiencia del Subcomité sobre la Infancia, la Familia, las Drogas y el Alcoholismo del Comité de Asuntos Laborales y Recursos Humanos del Senado de los Estados Unidos, abril 28, 1985, en el que se trataba de probar la ligazón entre Nicaragua, Cuba, Bulgaria, la Unión Soviética y el narcotráfico. Esta ligazón era intexpretada en términos de un plan geopolítico destinado a socavar a los Estados Unidos y financiar las campañas políticas de la izquierda a Latinoamérica; ver también las declaraciones de Paul Henze, ex-funcionario del Consejo de Seguridad Nacional de los Estados Unidos y consultor de la Rand Corporation ante la audiencia de 1984; citada en la nota NN1, asimismo ver declaraciones de Nathan Adams, editor del Reader's Digest, ibid. 
cientes y colectivos expresados en la metáfora de la "infiltración" de la "infección", de la lucha de la ley contra el caos delictual (sólo en Estados Unidos la policía tiene un rol heroico obsesivo como la gran barrera contra el "mal". Compárese con la tradición de la novela policial europea, donde el héroe es generalmente un diletante más o menos civil y más o menos excéntrico con respecto a fuerzas de orden burocratizadas y "torpes").

De esta forma la cruzada reaganiana contra las drogas fácilmente toma los aspectos de una cruzada policíaca de salvación frente al gran complot criminal que puede destruir a la sociedad. Con ello no hace otra cosa que expresar la construcción social dominante de la realidad en la población norteamericana.

En una primera fase -entre 1980-85 aproximadamente- los gobernantes norteamericanos tendieron a pensar que el grueso de los esfuerzos para remediar la difusión del uso de narcóticos, debían centrarse en la eliminación de los cultivos, reduciendo así la oferta. ${ }^{10}$ Después de la fecha mencionada, se esboza una política orientada también hacia el componente de la demanda interna. Es digno de subrayar que por mucho tiempo los estadounidenses tendieron a ver los hábitos de consumo de su población como dependientes de la disponibilidad de drogas, una disponibilidad mediada por la acción de organizaciones de traficantes. ${ }^{11} \mathrm{~A}$ juicio de los norteamericanos, el vicio interno sería paulatinamente asfixiado en la medida en que la erradicación e interdicción tuvieran éxito. Se insinúa aquí veladamente la idea de que la patología social sólo surge y se difunde como efecto de "algo" que penetra desde afuera a la manera de un agente patógeno. Era pues lógico pensar en destruir a este agente en su origen: en el lugar de producción o cultivo de la droga. Por supuesto que un paradigma alternativo era posible. Muchos políticos y gobernantes latinoamericanos han señalado que no habría estímulo para la difusión de los cultivos de materias primas para la confección de narcóticos, si no hubiese una demanda creciente desde los Estados

\footnotetext{
${ }^{[10]}$ La posición norteamericana se halla clara y suscintamente expresada en la entrevista a Ann Wrobelsky, Secretaria de Estado Adjunto para Asuntos Internacionales de Narcotráfico; publicada el 6 de diciembre de 1986 en el Boletín del Servicio Cultural y de Prensa de la Embajada de Estados Unidos en Santiago đe Chile.

[11]Ver Wrobelsky, entrevista citada. También "Análisis de la nueva ley de Estados Unidos contra la Narcomanían", Servicio de Cultura y Prensa de la Embajada de los Estados Unidos, Santiago de Chile, octubre 29, 1986; y Audiencia del Sub-Comité sobre la Infancia, la Familia, las Drogasy el Alcoholismo del Comité de Asuntos Laborales y Recursos Humanos del Senado de los Estados Unidos, marzo 13, 1985.
} 
Unidos. Aquí el "motor" del narcotráfico son aquellos que, dentro de Estados Unidos, y por las razones que sean, "llaman" a la droga y literalmente requieren de su cultivo, exportando su producción para así poder importarla como producto. ${ }^{12}$

Así, en la percepción corriente norteamericana la droga es complot criminal organizado; y es también acción patógena de lo "exterior" sobre un "interior" que podría mantenerse limpio y sano, de no ser por esta invasión de elementos nocivos desde "afuera". Así como el inmigrante ilegal destruye y distorsiona la cultura y los mercados laborales bien ordenados antes de su llegada, ese otro inmigrante ilegal -el narcótico- amenaza con desordenar a una sociedad bien armonizada previo a su perturbadora llegada de los mismos lugares de donde llega el bracero intruso. La invasión étnica y cultural de América Latina tiene su correlato simbólico en la invasión tóxica de sus plantas, vicios y drogas: el peyote, la marihuana, la coca, la mescalina o la amapola.

\section{Las políticas de Estados Unidos frente al narcotráfico}

A pesar de los crecientes esfuerzos educacionales propagandísticos destinados a apartar a la población norteamericana del uso habitual de sustancias narcóticas, el gobierno de los Estados Unidos sigue convencido de que la erradicación de cultivos mediante el uso de herbicidas es la forma más eficaz de eliminar el narcotráfico.

Esta política consiste en convencer a los países donde se cultivan las materias primas, de que inicien -generalmente con ayuda y asistencia técnica de Estados Unidos- un programa masivo de fumigación que destruya las plantaciones de coca, marihuana, amapola, etc. Se supone que al "secarse" la disponibilidad de estos productos, los traficantes no podrán seguir adelante con sus actividades. Una justificación más modesta, pero más realista de esta política consiste, no tanto en extirpar las especies culpables, sino en mantener el abastecimiento a niveles lo suficientemente bajos como para que los precios al consumidor del producto refinado se mantengan altos; dificultando así la entrada de nuevos consumidores al mercado.

El problema que puede producirse, es que dada la bajísima elasticidad de la demanda por estas drogas, lo que se consiga en

[12]Entrevista con un ex-Ministro boliviano, junio 1986. Ver también South, op. cit 
realidad es aumentar el poder del traficante frente a su clientela, y de hecho, empujar a los usuarios a conductas criminales cada vez más extremas. Asimismo, al encarecer la droga, se produce una concentración del uso del mejor producto en los estratos de más altos ingresos, con lo cual se estimula la drogadicción de la clase empresarialy de la alta burocracia, con efectos peligrosos sobre la conducción de la vida económica y política del país. Por otra parte, en la búsqueda de mantener la clientela menos pudiente, los traficantes desarrollan productos de inferior calidad química, y por tanto de una toxicidad mucho mayor; con lo cual se multiplican grandemente los efectos dañinos sobre la masa de usuarios. ${ }^{13}$

Dentro de la lógica de su política anti-drogas, los Estados Unidos aspiran a internacionalizar al máximo sus alcances. Para ello buscan integrar al mayor número posible de países en la implementación de estas políticas. ${ }^{14}$

Tal aspiración no es necesariamente fácil de lograr. Muchos países no comparten el diagnóstico norteamericano, ni los alcances internos del problema son tales que induzcan a estos países a hacerse partícipes de la urgencia de Washington. Por otra parte muchos de estos países deben pagar altos costos sociales, políticos y económicos si desean sumarse a la cruzada reaganiana contra los estupefacientes.

De hecho, en varios países estas reservas se traducen en la sensación de que la política norteamericana no es sino una forma de transferir a países extranjeros el costo de una política cuyos beneficiarios principales son los Estados Unidos. Son los países y gobiernos productores los que deberán pagar los costos de oportunidad de ganancias no realizadas, de dislocación social en las áreas productoras, de violencia y resistencia política, de gasto en equipos, personal e instalaciones. Por otra parte la ayuda que Estados Unidos ofrece para aliviar tales costos, es considerada siempre una fracción muy menguada del costo real que para los países productores tiene erradicar los cultivos.

\footnotetext{
[13]Un ejemplo es la aparición del "crack": una forma "barata" de la cocaína que tiene una toxicidad más alta que la forma pura y que multiplica los efectos secundarios dañinos de la citada droga.

[14]Ver Audiencia citada, marzo 13, 1985, Senado de los Estados Unidos. También: Texto Oficial de las declaraciones del Presidente Reagan al firmar la nueva Ley Anti-Narcóticos, el 27 de octubre de 1986. Servicio de Cultura y Prensa de la Embajada de los Estados Unidos en Santiago de Chile. Declaraciones de John Thomas, Secretario de Estado Asistente para Asuntos Internacionales relativos a los Narcóticos, "Narcóticos en América Latina", Material de Consulta del Servicio de Culturay Prensa de la Embajada de los Estados Unidos en Santiago de Chile, junio 16, 1987
} 
La política norteamericana contra el tráfico y producción de narcóticos no sólo busca comprometer la activa cooperación de otros países en términos bilaterales, sino que ha buscado también canalizar dicha preocupación a través de conductos multilaterales. ${ }^{15}$ Así, los Estados Unidos han presionado a ciertos organismos financieros para que incluyan dentro de sus criterios para el otorgamiento de préstamos, el grado de compromiso del país receptor con las campañas anti-droga. ${ }^{16}$ Asimismo, se ha buscado involucrar a organismos políticos como la OEA, Naciones Unidas, etc. Así, en 1986, Estados Unidos patrocinó la resolución adoptada, por la 16a. Asamblea General Ordinaria de la OEA en el sentido de establecer una Comisión Interamericana para el Control del Abuso de Drogas. También ha habido intentos por coordinar esfuerzos a niveles sub-regionales, ejemplo de los cuales es la declaración de Puerto Vallarta con 12 países latinoamericanos y del Caribe, en el que se eleva el nivel de la cooperación anti-narcotráfico.

Pero, junto con la acentuación de los esfuerzos por reducir la producción de materias primas para la fabricación de drogas, a partir de 1985, la administración Reagan inició esfuerzos para atacar el consumo interno, mostrándose así receptiva a las críticas de sus socios extranjeros en el esfuerzo de erradicación. ${ }^{17}$

Estas nuevas políticas han tenido dos ejes fundamentales: aumento de controles, vigilancia y represión del tráfico y consumo; y acciones educacionales tendientes a disuadir a la población joven.

Algunas de las iniciativas de Reagan fueron muy polémicas; como aquéllas tendientes a implantar controles obligatorios antidoping entre deportistas, empleados públicos, personal con funciones de seguridad, e incluso promover el uso rutinario de tales controles en lugares de trabajo dentro del sector privado. Este intento de establecer formas de vigilancia selectiva sobre ciertos grupos de la población ha tropezado con fuertes críticas, tanto desde el punto de vista de su eficacia como desde el punto de vista de las libertades

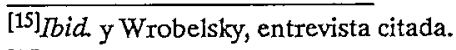

$[10]$ J. Thomas, op. cit

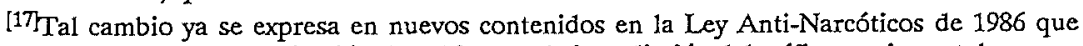
enfatiza -junto a la erradicación de cultivos y a la interdicción đel tráfico-acciones tales como programas de prevención, tratamientos y rehabilitación dirigidos al personal del sector público; campaña contra la đrogadicción escolar; aumento đe fondos para el tratamiento de la narcomanía; aumento de las penas para el tráfico de drogas; establecimiento de una nueva oficina de Prevención de Abuso de Sustancias Químicas; campañas en los medios de comunicación; etc. 
civiles, tema frente al cual el público norteamericano es particularmente sensible.

Junto con ello, el Congreso aprobó una severa ley anti-narcóticos que aumenta las penas para los traficantes; asigna 1.700 millones de dólares para tratamiento de toxicómanos, educación y otros programas preventivos; investigación y represión del tráfico, aumento del personal para el patrullaje de zonas fronterizas; criminaliza el "lavado" de dineros provenientes del tráfico de drogas; establece la confiscación de bienes de los narcotraficantes convictos; y fortalece la vinculación entre ayuda externa y los esfuerzos anti-droga de los países potencialmente receptores.

Todos estos pasos gozan de un apoyo mayoritario en las opinión pública -salvo las ya señaladas medidas de centro mediante tests- y constituyen una de las áreas de política interna y externa donde el actual gobierno republicano goza una base más fuerte de apoyo.

Los problemas para la política norteamericana anti-droga, comienzan realmente una vez que se trata de coordinar acciones con otros países. En general la mayoría de los países productores han mostrado poco entusiasmo por el enfoque policíaco que han tratado de imponer los norteamericanos. Como se señalaba más arriba, se considera que Washington quiere exportar los costos de un problema cuyas raíces son internas ante todo.

A raíz de estas críticas, los Estados Unidos han debido ejercer vigorosísimas presiones diplomáticas y económicas para entusiasmar finalmente a algunos países en su campaña. Pero también, han debido buscar diseñar otras estrategias aparte de la interdicción y la fumigación. Una de ellas ha sido la de promover políticas de sustitución de cultivos. Estas han tenido hasta ahora un carácter experimental y piloto; pero ya han tropezado con algunos graves problemas. El principal es que las plantaciones de materia prima para la droga son mucho más rentables que cualquier otra alternativa que se ofrezca. Por otra parte, en algunos casos, las especies vegetales de las que se fabrica la droga son cultivos tradicionales de valor no sólo económico, sino que cultural, ritual y nutricional, muy importante para la sociedad campesina. ${ }^{18}$ Algunos de estos cultivos tienen usos alternativos legítimos y fuertemente asociados al modo

[18]Ver, Baldomero Cáceres, "El problema de la coca en el Perú", Socialismo y Participación, Lima, marzo, 1983. 
de vida de los pueblos que los cultivan. Su abandono por otras alternativas implica costos no sólo económicos, sino que emocionales y socio-culturales.

De esta forma, las políticas de sustitución de cultivos topan con resistencias "populares" no muy diferentes a la que despierta la fumigación, la erradicación y la persecución policíaca. Por otra parte, las autoridades locales se quejan a menudo de que cualquier política de sustitución exitosa debe hacerse en gran escala y con recursos importantes que no sean una fracción irrisoria de los beneficios de la "narco-economía". A muchos les cuesta ver cómo proyectos de pocos millones de dólares pueden generar incentivos capaces de contrapesar los que provienen de operaciones en el circuito de la droga, que ascienden a varios miles de millones de dólares anualmente.

El componente policíaco de la lucha contra la droga ha experimentado también una evolución. Por una parte los norteamericanos han presionado a fin de lograr incrementar la participación, libertad de maniobra y presencia de sus funcionarios policiales en los países productores. ${ }^{20}$ Junto con ello se ha procurado incrementar la jurisdicción de los tribunales norteamericanos por mẹedio de tratados de extradición excepcionalmente fluídos, e incluso sin precedente legal, dentro de las prácticas constitucionales de los países contraparte (i.e. Colombia). ${ }^{21}$ Así, se ha procurado acelerar la entrega por parte de algunos países latinoamericanos de sus ciudadanos acusados de traficar drogas en Estados Unidos; mientras que la presencia de agentes policiales norteamericanos dentro de los aparatos locales ha tendido a hacerse permanente y mucho más profunda.

En segundo término hay una tendencia a superponer una dimensión militar sobre la policíaca. De esta manera, en las operaciones anti-droga hace su aparición personal del ejército, infantería de Marina y Cuerpo de Guardacostas. En las operaciones realizadas durante 1986 en Bolivia y en años anteriores en México, el diseño

\footnotetext{
${ }^{[19]}$ Sobre la importancia económica de la droga para países como Perú, Colombia y Bolivia, yer, The Guardian Weekly, enero 11, 1987; artículo firmado por Marcel Niedergang.

[20] Ver Audiencia citada, marzo 13, 1985. Senado de los Estados Unidos para el rol de policías norteamericanos en Colombia, "Las dimensiones đel narcotráfico" Estrategia Económica y Financiera, Bogotá, noviembre, 1985.
}

[21] Ibid. 
personal y equipos fueron netamente militares. ${ }^{22}$ De esta forma existe un proceso de desplazamiento perceptual que va haciendo de la lucha contra la droga, no un problema de combate al delito, sino que más allá de ello, una especie de operación de guerra de baja intensidad que responde a una problemática de seguridad nacional. $^{23}$

Así, la lucha contra el narcotráfico reviste paulatinamente el aspecto de una guerra y el problema de la droga se ve como fruto de una agresión dirigida explícitamente a socavar las bases de la sociedad. ${ }^{24}$ De tal manera que las medidas para contrarrestar este flagelo comienzan a insertarse en un horizonte mental en que el tipo de recursos y los marcos de lo permitido no son ya los de tiempos "normales" ni los de la diplomacia de paz, sino los de una emergencia bélica total. El conjunto de los participantes y cómplices son indistintamente vistos como "enemigos"; desde el vendedor callejero, hasta el campesino cultivador de coca o marihuana, pasando por el traficante o el químico de los laboratorios de procesamiento. En este marco es fácil concluir que todos y cada uno de ellos están envueltos en una gigantesca conspiración intencional y estratégicamente orientada para hacer daño a la nación americana. Asimismo se hace plausible buscar conexiones entre estos enemigos y otros enemigos involucrados en otros conflictos con los Estados Unidos: guerrillas marxistas, la Unión Soviética, movimientos terroristas del Medio Oriente, etc. Los Estados Unidos han visto aparecer una serie de nociones y políticas fundamentadas en la idea de una convergencia intencional de todos los actores que representan un peligro a los ojos de la opinión pública interna. Este "monismo" en la concepción del enemigo, esta búsqueda de colapsar todos los conflictos y amenazar en una sola gran guerra, subyace en buena medida en las tendencias a militarizary a "belicizar" el problema de la droga. Esto sin duda tiene

\footnotetext{
[22]Sobre la operación "Blast Furnace", ver artículo de fondo sobre dicha operación en la eđición de Newsweek, enero 26, 1987. Sobre la operación "Cóndor" en México, Richard Craig, "Operation Condor. Mexico's Anti-Drug Campaign Enters a New Era", Joumal of Interamerican Studies and World Affairs, agosto 1980.

${ }^{[23]}$ El concepto "guerra de baja intensidad" ha adquirido una cierta boga en los círculos estratégicos estadounidenses en los últimos 7 años. Se utiliza para referirse al uso de métodos militares que no implican una intervención abierta, en gran escala, de fuerzas norteamericanas. Puede hacerse a través de grupos pequeños especializados (SWAT teams) o de agentes locales (i.e. la "contra" nicaragüense). Se trata de ejercer presión bélica sobre el enemigo, sin por ello pagar los costos políticos y humanos de una intervención abierta de corte tradicional.

[24] Ver audiencias del Senado citadas más arriba.
} 
Fernando Bustamante / La política de Estados Unidos contra el ...

serios impactos en el manejo en "terreno" de las realidades locales vinculadas a la producción de estupefacientes. En general, son muy distintas las políticas que se derivan de un "monismo" como el citado, de una postura que considera el fenómeno de la droga como un complejo de conductas muy variadas, que involucran a actores muy diferentemente motivados y que se coordinan de manera fluctuante y flexible sobre la base de racionalidades muy diferenciadas y a veces incluso incompatibles. Que haya un resultado determinado no implica que el conjunto de los dispares sujetos que han contribuído a producirlo lo hayan anticipado estratégicamente, o que hayan sido unánimemente movidos por motivaciones u orientaciones similares. Es difícil pensar que un vendedor callejero de drogas de Nueva York, esté pensando o siquiera le preocupe el impacto macrosocial o político de su pequeño tráfico; las raíces de su conducta deben buscarse en cálculos y necesidades mucho más microsociales y prudenciales, o sea "apolíticos". Obviamente que la resistencia de los campesinos bolivianos a la Operación Blast Fumace obedece a otros motivos, pero también es dudoso que los mueva un odio ideológico hacia los Estados Unidos o una malevolencia hacia su sociedad.

Pero, sea como sea, es frecuente hallar entre los formuladores de la política norteamericana respecto al tráfico de drogas una tendencia a plantear soluciones basadas sobre el paradigma de la "guerra" y de la lucha entre dos bandos, en el que cada uno de los cuales puede ser tratado como un sujeto racional unificado, movido por cierta malevolencia hacia su contendor. Estas políticas son muy diferentes a las que se desprenderían de un modelo de consecuencias no anticipadas de muchos actores diferencialmente motivados $\mathrm{y}$, posiblemente, mutuamente indiferentes.

\section{Los problemas de implementación en América Latina de la política norteamericana anti-narcóticos}

La visión que acabamos de bosquejar tropieza con una serie de problemas en su confrontación con la realidad de los países y áreas productoras de materias primas para la producción de drogas. La Operación Blast Furnace, llevada a cabo en Bolivia durante el año 1986, nos puede servir para ilustrar e introducir la discusión de estas complejidades. 


\section{ESTUDIOS INTERNACIONALES}

Dicha operación fue concebida como una acción conjunta de las policías especializadas de Estados Unidos y Bolivia, con apoyo de tropas aerotransportadas del ejército norteamericano. En esta operación se intentaba eliminar los cultivos de coca en el Chaparé y el Beni, destruir los laboratorios procesadores y perturbar lo más posible las redes de traficantes, tratando de arrestar a la mayor cantidad posible de éstos. La operación fue planeada como una verdadera acción bélica, con "asaltos" sorpresivos en helicóptero, con ocupación de pueblos y fincas, registros casa por casa, vigilancia aérea, cerco y rastreo con apoyo de infantería a los detectives y policías. ${ }^{25}$

Esta operación tenía como precedente la Operación Cóndor desarrollada en México a partir de 1975, aunque en ésta última no habían participado tropas, sino tan sólo agentes civiles de la policía federal anti-drogas de los Estados Unidos. La operación mexicana había tenido éxito en disminuir sensiblemente los cultivos mexicanos de adormidera y marihuana, especialmente en el estado de Sonora, el más penetrado por el poder de los narcotraficantes. ${ }^{26}$

La Operación Cóndor había tomado rápidamente el cariz de una verdadera guerra anti-campesina. A través de ella fue pronto evidente que el Gobierno Federal mexicano buscaba más que una simple operación profiláctica anti-droga; se intentaba, y de hecho se apuntaba a reafirmar el control político del Estado central sobre la población rural y semi-rural de la zona. El negocio de la droga se presentaba como una actividad generalizada que directa o indirectamente articulaba al campesinado, a los caciques políticos locales, a sectores empresariales provincianos, al comercio urbano. El control sobre la producción y comercio de la heroína eran parte de un circuito más complejo de lealtades y reciprocidades políticas, por parte de una población poco dada al consumo de tales drogas, pero habituada desde antiguo al cultivo y a la existencia de estos productos. Desde la perspectiva de este hinterland tradicionalista y alejado del control centralizante del Estado "moderno" y de su legalidad normativizada, la adormidera era otro cultivo más, que podía insertarse dentro de los horizontes de la cultura económica de la agroexportación y de las bonanzas que cíclicamente aceleran el lento ritmo de la vida en las sociedades tradicionalistas y familísticas. Este producto, al igual que

[25]Ver artículo citado de Newsweek; también entrevista a Wrobelsky, entrevista con un Coronel del Ejército norteamericano, Washington, D. C., 1987 (realizada por el autor).

${ }^{[26]}$ Craig, op. cit. 
Fernando Bustamante / La política de Estados Unidos contra el ...

tantos otros en la historia de los hinterlands de América Latina se presentaba como una fuente más de ingresos excepcionales que permitían vigorizar los procesos de formación de lealtades y de identidades familísticas que focalizan los procesos de acumulación económica en las sociedades "interiores" de la América Latina tradicional. $^{27}$

Para los líderes políticos y sociales locales, que llegaban incluso al control de los niveles de gobierno estadual, la ofensiva de México D.F. y sus asesores estadounidenses, representaba la presión de "extraños" sobre la identidad y la autonomía de la sociedad local; un intento de arrebatarle las ventajas azarosas y transitorias del ciclo de bonanza y de coartar la capacidad de las élites locales para cumplir sus funciones de articulación de la sociedad local. De esta forma Sonora, tal como más adelante el Chaparé en Bolivia, se convertirían en verdaderas "Fuenteovejunas" que resistirían con todos los medios a su alcance esta presión de un Estado burocrático, lejano y abstracto, que por serlo se presentaba como incomprensible, foráneo y por tanto enemigo. Esta visión del Estado legal como enemigo surge de la lógica de las reciprocidades familísticas, para las cuales la negativa a intercambiar y a pasar a formar parte de la "familia" simbólica de las redes clientelares locales representa una verdadera declaración de voluntad destructiva y antagónica de las identidades que este familismo clientelista constituye.

De esta forma, la ofensiva anti-droga termina por revestir alcances mucho más profundos que los concebidos en la mente de sus planificadores. Se convierte en otro episodio de la guerra de una modernidad centrípeta y racional-burocrática en contra de los particularismos tradicionales de las sociedades "periféricas". Estas sociedades no pueden compartir ni entender las razones de la persecución contra su empresa común, basada con frecuencia en el aprovechamiento de recursos vernáculos cuyo impacto nocivo sobre el mundo exterior les resulta incomprensible o indiferente.

\footnotetext{
[27]E1 término "interiores" no connota necesariamente un rasgo geográfico. Se refiere en realidad a universos sociales "vernáculos" que no se representan fácilmente a través đel modelo heurístico de la "sociedad civil". Su mecánica de funcionamiento obedece a otros principios sociales. Es sugerente ver la operación de estos mecanismos en la formación del "ethos" político de las masas populistas urbanas, i.e. Amparo Menéndez Carrión, La Conquista del Yoto: de Velasco a Roldós, Quito, 1986, s.e.; donde se estudia la forma como la presencia de mecanismos no modernos de formación de identidades colectivas pueden operar con gran fuerza en el seno de una metrópoli como Guayaquil.
} 
Cuando el Estado central ataca a la sociedad local "productora" de droga, lo hace en nombre de valores y razones "exóticas", con ayuda de extranjeros y en aras del bienestar del extranjero. De esta forma se plantean las premisas para una reacción de tipo "populista", en la cual los hijos del aquí, del más acá, y de la tierra se enfrentan a intrusos que vienen del allá, de afuera y de las alturas. De esta forma, se hace posible una conexión de sentido de tipo simbólico y emotivo, entre este sentimiento latentemente populista de la sociedad familística local y grupos políticos -armados o no- que buscan asentar su acción en una canalización de lo "popular" hacia luchas dirigidas contra el Estado o en referencia a él: sea para destruirlo desde afuera, a través de una especie de "anarquismo primitivo" (al estilo Sendero Luminoso) -anarquismo que sólo lo es en términos del concepto moderno, racional-legal del orden político- o bien como la penetración del Estado por camarillas cacicales que buscan reorientar sus poderosos recursos hacia los horizontes sociales definidos por el mundo de lo "popular", tal como ha venido ocurriendo en el caso boliviano, con un aparato estatal penetrado y desarticulado por particularismos locales y sociales de distinto tipo.

En este contexto, la política norteamericana necesariamente empuja a los Estados a agudizar sus conflictos con el mundo tradicional del hinterland. Dependiendo del carácter de los conflictos y de los balances entre las diferentes esferas sociales involucradas, la presión estadounidense tendrá distintos efectos.

En México, por ejemplo, donde la oposición entre el caciquismo y el Estado Federal pasa por periódicos ciclos de exacerbación, la Operación Cóndor dio lugar a una verdadera "guerra" del Estado contra la sociedad de Sonora. En este caso, la distancia entre ambos ámbitos permitió una acción vigorosa y concentrada contra las redes locales de poder, las cuales iban desde el gobernador del Estado a los pequeños campesinos cultivadores. En esta verdadera "guerra campesina" el Estado pudo actuar con un alto grado de indiferencia con respecto a la sociedad local, lo cual permitió una aplicación sistemática, eficaz e intensa de la violencia y del poder físico contra el mundo de la droga. Los poderes locales involucrados en este tráfico tenían pocos "contactos" con el poder central y lo tenue de la influencia de su racionalidad familística sobre el distrito federal, les impidió aplicar presiones suficientemente eficaces como para sabotear "desde adentro" los esfuerzos del gobierno. 
Fernando Bustamante / La política de Estados Unidos contra el ...

De esta manera, la presión estadounidense para que los gobiernos de la región incrementen su lucha contra el narcotráfico y para que se asocien vigorosamente a las políticas promovidas desde Washington, contribuye a acelerar la agudización de las contradicciones entre el mundo oficial de un Estado más o menos burocratizado y el mundo "popular" de quienes no reconocen su identidad política en el conjunto de valores normativos que constituyen tal ámbito de racionalidad y acción social.

El resultado de estos enfrentamientos depende en buena parte de los recursos al alcance de los distintos actores. Para los aparatos estatales resulta difícil llevar el peso de esta lucha, en la medida en que los recursos que puede poner al servicio de la cruzada anti-narcóticos se ven restringidos por los problemas económicos y fiscales que afectan a la mayoría de los Estados. De hecho, las autoridades nacionales han señalado que la ayuda norteamericana es demasiado pequeña comparada con los costos de oportunidad que la lucha contra la droga representa y con los recursos que los grupos beneficiarios del tráfico pueden movilizar. Estos recursos no sólo son de tipo financiero, sino que se apoyan también en la utilización re-potenciada de redes de lealtad afectiva basadas en reciprocidades extra-económicas.

La presión estadounidense para forzar a los Estados a incrementar su control y policía hacia el interior, tiene con frecuencia la paradójica consecuencia de someter a estos Estados a tensiones y desafíos que no siempre están en condiciones de enfrentar sin provocar la movilización reactiva de mecanismos alternativos subyacentes de control y mediación social que los limitan tanto como exterioridad como en tanto "otredad" interna, a la manera de la reaparición de una forma de conciencia y de ser normalmente reprimidas por el pensamiento iluminista Estado-céntrico de las élites políticas latinoamericanas. $^{28}$

Así, los Estados se ven encarados por un hinterland alienado, pero también erosionados desde adentro por las tentaciones renovadas de un familismo cuyo particularismo valórico puede servir como coartada para el aprovechamiento colectivo de los beneficios de la droga.

\footnotetext{
${ }^{[28]}$ Sobre el carácter y problemas de esta concepción "iluminista" y sus consecuencias en términos de la dificultad de comunicación de las élites políticas con el mundo de lo "popular" recomendamos de Carlos Pareja, "Más allá de los Mitos del Progreso", Cuademos del CEH, Ne 50, Montevideo.
} 
ESTUDIOS INTERNACIONALES

En los Estados Unidos ciertos sectores han buscado ligar el narcotráfico con los fenómenos de subversión política armada. En general, los esfuerzos en este sentido han buscado demostrar lazos entre los movimientos guerrilleros de izquierda y los traficantes, sugiriendo que éstos se hallan integrados operativamente y que de forma más o menos explícita han coordinado sus esfuerzos en pos de objetivos comunes. Así narcotraficantes y guerrilleros formarían parte de una misma "conspiración" cuyo mando final estaría localizado en los países del bloque socialista (Cuba, Bulgaria y Unión Soviética). ${ }^{29}$

No se trata aquí de entrar a un análisis detallado de la veracidad o plausibilidad de tales investigaciones. Parece claro, sin embargo, que, en algunos casos tales vinculaciones tienen cierta base de realidad.

El problema no estriba en determinar si existen o no contactos entre los grupos guerrilleros como el FARC, el M-19 o Sendero Luminoso con las redes de narcotraficantes, sino en entender el sentido y naturaleza de tal relación.

Las relaciones que han podido sustanciarse entre ambos sectores son de los siguientes tipos:

a) Los narcotraficantes han actuado como agentes de los guerrilleros en los mercados negros de armas. Los guerrilleros han utilizado los contactos de los traficantes para analizar su propio abastecimiento de equipos.

b) Los traficantes han "comprado" protección de las guerrillas en las áreas donde éstas tienen poder.

Sin embargo, debe señalarse, que en dichas zonas no sólo los narcotraficantes pagan a la guerrilla, sino que también los sectores legales de la economía local. En Colombia, por ejemplo, el FARC ha establecido en las áreas que controla, las bases de un rudimentario sistema de protección, policía y tributación. Los empresarios, comerciantes y agricultores deben contribuir a las áreas del Frente, del mismo modo como quienes viven en zonas controladas por el gobierno deben pagar impuestos y, a veces, suplir las deficiencias de las fuerzas de orden oficiales alquilando los servicios de vigilantes privados, guardaespaldas o, incluso, organizar ellos mismos grupos paramilitares o "guardias blancas". En el citado contexto, la guerrilla recolecta fondos como lo hace el propio Estado. Los narcotraficantes

[29]Ver audiencias del Senađo đe los Estados Unidos, citadas más arriba. 
no pueden ser fácilmente separados o distinguidos del campesinado "normal" o del conjunto de las clases mercantiles de los hinterlands. Sus bases sociales se compenetran e imbrican a todos los niveles de la sociedad local. De tal modo, cuando la guerrilla se enraíza en ella y se identifica con ella puede fácilmente ser vista como la milicia extra-oficial de la comarca, no mucho más molesta o depredadora que los vigilantes mercenarios o que las policías municipales, provinciales o estatales.

De hecho, en aquellas zonas donde la economía narcotraficante convive, no con los movimientos anti-estatales sino con las autoridades "legales", los pagos y prestaciones mutuas fluyen con igual intensidad. Allí donde la guerrilla domina, todos los que tienen algo que salvaguardar deben pagar a la guerrilla; allí donde domina el Estado, se tejen análogas relaciones con las burocracias públicas. Los traficantes entonces sobornan y financian a los aparatos de seguridad "oficiales". En ambas situaciones los aparatos armados forman parte de la "escena local" y deben ser mantenidos por ella. Los narcotraficantes forman también parte de esa misma "escena local" y como parte de ella deben entrar en múltiples tratos, entendimientos y transacciones con los monopolistas locales del poder de fuego, sin cuyo concurso no sería fácil llevar adelante los negocios de la vida diaria.

El negocio de la droga no es en estos hinterlands un mundo cerrado, oculto y apartado de la interacción civil cotidiana. En este sentido, verlo de tal manera es fruto de una perspectiva experiencial muy propia de las fuerzas de orden centrales, no involucradas con la sociedad local. En efecto, frente a las burocracias normativizadas nacionales o internacionales, los "narcos" deben vivir clandestinamente y presentarse como un "aparte" radical; como el lado oscuro de la socialidad, como su otredad, esfera de lo secreto, sumergido, diferente y separado. El trato con esta esfera es, en efecto, el trato con el "otro", con un mundo más allá de la socialidad común. Pero tal no es la situación de quienes explotan el negocio de la droga frente a las sociedades locales en las que viven. Frente a ella no son extraños, ni extranjeros. Son los mismos comerciantes, agricultores, campesinos, empresarios de la zona; son personas cuyas familias pertenecen a ella y tienen una ya larga historia de lazos con la tierra y con otras familias en la región. Nada tienen en 
común con las "mafias" urbanas de los Estados Unidos, por ejemplo, protegidas por el anonimato de la gran ciudad y enfrentadas día a día a un entorno social del cual son los recién llegados misteriosos y diferentes.

Así pues, en la medida en que las guerrillas se insertan como parte de la resistencia "popular" contra el Estado y se hacen expresión de la contra-violencia local contra éste, deben establecer lazos funcionales de tipo proto-estatal con todo este universo, en el cual los sectores ligados a la droga son parte "natural" del paisaje.

Cabe enfatizar que el uso del término "pueblo" y de "lo popular" en este contexto, no dice relación a la lucha de clases. El sentido de lo popular se refiere a la reivindicación y afirmación de un modo de vida, de una forma de fundamentar los lazos sociales entre las personas. El referente de lo "popular" se aproxima a la noción de Gemeinschaft tal como lo articulara Ferdinand Toennies. "Pueblo" son todos aquellos actores insertos en un modo de existencia cotidiana constituida sobre la base de la lealtad familística, en torno a nociones de valor personal no mercantilizadas y sobre un referente societal concreto: este grupo humano histórica y espacialmente situado, formado por todos los que están dispuestos a vincularse a través de relaciones de intercambio ajenas a la mercantilización y la fundamentación de lo colectivo en formas normativas abstractas e ideales. "Pueblo" representa a los que se reconocen como integrantes de una misma forma de socialidad basada en una racionalidad de valores sustantivos y lealtades hacia personas o grupos, más que hacia ideas o nociones abstractas del bien común.

En este universo, el empresario puede relacionarse hacia el exterior a través de la forma mercancía, pero no puede aplicar tal forma a sus relaciones al interior del pueblo; frente a dicho entorno societal, su proceso de acumulación debe ser el punto de partida no de más acumulación, sino que de una red cada vez mayor de beneficiencia, favoritismo y prebendalismo paternalista, que lo une afectiva y concretamente a todos aquellos que se le vinculan. En este aspecto "interior" del proceso, las clases no se constituyen abstractamente como tales y el peón o el campesino se sienten parte de la misma esfera de identidad que el latifundista o el gran traficante. Este último

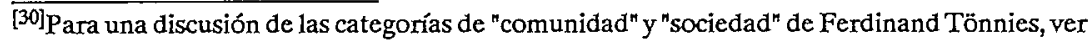
la colección de ensayos publicada a raíz del Simposio Ankunft Bei Tönnies realizado en Kiel, República Federal Alemana en 1980 y publicado por Walter G. Mühlau Verlag, 1981. 
es parte del pueblo en la medida en que frente a su sociedad interior se comporta, al menos en parte, como si para él no existiera la acumulación mercantil. Las capas empresariales locales son "pueblo" en la medida en que hacia sus coterráneos suspenden la operación de la ley del valor -o la limitan- protegiéndolos de sus posibles embates disolventes. Así, la función de los grandes "padrinos" del tráfico de drogas es la de generar una acumulación económica que les permita aislar a la sociedad tradicional de las presiones de la modernidad y fortalecer las barreras que ésta pone al disciplinamiento que esporádicamente intentan las élites estatistas "iluministas".

El tráfico de drogas no es visto por el "pueblo" como un delito, pues el concepto de delito en el cual tiene sentido definir al narcotráfico como crimen, requiere de una compleja serie de supuestos previos universal-abstractos. Requiere, por ejemplo, el reemplazo de las nociones de "transgresión" con las que operan las sociedades tradicionales: el disciplinamiento de la población en torno a la idea del "delito"; el concepto del buen ciudadano como aquel que no delinque, o sea aquél que vive de acuerdo a un sistema altamente articulado y explícito de normas codificadas como una gramática de la conducta posible; es una "conquista" reciente de la modernidad. Así lo atestigua la historia de los combates seculares de los Estados para obligar a las poblaciones a guiarse por la ley y no por la costumbre, por el código y no por el sentido común, por la universalidad ética y no por las metáforas del honor y la lealtad.

De esta forma, las poblaciones del interior tienen serios problemas para lograr una comprensión ética de lo "delictual" del narcotráfico. La persecusión contra éste se presenta como fruto de la "animadversión" de extraños, más que como un efecto de una violación de la ley y del orden. Ley y orden cuya gramática ideal está lejos de haberse asimilado y hacer sentido.

Un ejemplo claro de esto es la reacción que en la ciudad de Medellín provocó el arresto y la extradición de Carlos Lehder Rivas, uno de los "capos" del narcotráfico colombiano. Para amplios sectores sociales del departamento de Antioquía, Lehder es un benefactor, un filántropo y un "notable" local, no un delincuente. Su arresto fue resistido por grupos que iban mucho más allá del círculo estrecho de una mafia delictual y provocó una fuerte alienación en amplios sectores de la sociedad local. ${ }^{31}$

[31]Ver Mensaje Iberoamericano, № 370, octubre 15, 1986, Madrid, España. 
De lo señalado se desprende que las relaciones entre la guerrilla y el narcotráfico deben ser entendidas como parte de una lógica socio-política "popular" que no puede ser ubicada dentro de los marcos y requerimientos de la política "moderna". Cabe señalar por último, que la mayoría de los movimientos guerrilleros implicados no constituyen casos claros o "típicos" de guerrillas castristas. Sus raíces históricas e ideológicas se remontan a otras fuentes, y en ellas el componente populista o agrarista parece mucho más claramente perfilado que una identidad marxista-leninista y proletaria; lo cual por otra parte, se compadece con el hecho de que el carácter social de las clases trabajadoras en sus zonas de implantación guarda poca relación con el modelo "clásico" que la tradición política occidental y burguesa ha imputado a los grupos subordinados a la moderna sociedad de clases.

En el caso de Sendero Luminoso en Perú, la circunstancial relación de la guerrilla con el narcotráfico es compleja de una manera distinta.

En la conducta de Sendero Luminoso hay una clara diferenciación entre la actitud hacia la producción de coca, de productos derivados tradicionales y los usos consuetudinarios característicos de la cultura campesina-indígena, y el tráfico y consumo de derivados altamente refinados de la hoja de coca. ${ }^{32}$

Sendero Luminoso ha protegido las prácticas tradicionales de cultivo y consumo de la coca en contra de los programas de erradicación. Esta postura forma parte de una política de defensa étnica. La coca se presenta como símbolo y como instrumento de la identidad cultural del campesinado quechua de la sierra peruana. Los esfuerzos de erradicación del cultivo de la coca son percibidos como un ataque contra la identidad y la existencia misma del pueblo indígena. El agrarismo "nativista" de Sendero Luminoso se moviliza en contra de la erradicación como fruto de un compromiso romántico con lo quechua-andino.

En cambio, el narcotráfico y la drogadicción son virulentamente reprimidos por las fuerzas de Sendero Luminoso. El uno y el otro son vistos como explotación extranjera blanco-mestiza o de un recurso propio de los indígenas. El traficante es atacado por mer-

\footnotetext{
[32] En efecto, el consumo campesino se reduce a la hoja de coca, la cual no es una droga. La "pasta" de coca, o el clorhidrato de cocaína son productos elaborados que son ajenos al uso vernáculo trađicionalmente aceptado.
} 
Fernando Bustamante / La política de Estados Unidos contra el ...

cantilizar la vida indígena y por introducir criterios de ganancia que rompen la pureza de la "comunidad natural" mimetizándola e insertándola en los (perversos) circuitos de la acumulación. Asimismo, el fuerte componente moralista/fundamentalista del "ethos" senderista se crispa en contra del consumo y venta de derivados intoxicantes de los cultivos tradicionales. Así allí donde han podido los senderistas han ejercido una violentísima represión en contra de los traficantes y de los drogadictos que han caído en sus manos; pero, asimismo, han atacado implacablemente a los agentes gubernamentales dedicados a promover la erradicación del cultivo de la coca. Sendero Luminoso tiene pues una política anti-drogas; sólo que ella es muy diferente a la propiciada por el Estado y por los Estados Unidos. La lucha contra la droga pasa por una vuelta a la pureza de la sociedad andina no contaminada por los vicios y debilidades morales de la sociedad urbana y blanco/mestiza, de la cual el narcotráfico es visto como prolongación. Pero, al mismo tiempo, esta defensa pasa por la defensa a ultranza de la producción de coca como parte de esa reafirmación del modo de vida tradicional. Para los estadounidenses, la política senderista parece una colusión con los narcotraficantes porque se rehusa a sumarse a su particular estrategia estatal de combate an-ti-drogas, porque protege el cultivo de la coca y a los campesinos dedicados a ella. Pero tal percepción es insensible a que tal actitud de Sendero Luminoso no obedece a una "colusión" con el narcotráfico, sino a un programa anti-narcotráfico asentado en premisas y respuestas radicalmente diferentes a las que emanan de la modernidad cosmopolita que busca imponer, al menos en este tema; la política de los Estados Unidos.

El caso boliviano presenta características mixtas. Por una parte, al igual que en el Perú, la defensa de los cultivos de coca es la defensa de una actividad tradicional del campesinado quechua y de una identidad cultural; pero al igual que en Colombia, la tarea organizativa y directiva está en manos de cacicazgos empresariales locales, sin un carácter político o mesiánico. En vez de la pequeña intelectualidad provinciana y romántica de la sierra peruana, se trata de una red societal apolítica parecida a la colombiana, la cual, sin embargo, a pesar de su carácter no indigenista, termina cautelando mejor que cualquier vanguardia política estatista, la au- 
tonomía y el modo de vida campesino. La confabulación implícita de la oligarquía narcotraficante y el campesinado se asienta en arreglos que no requieren de modificaciones mayores del modus operandi del caciquismo tradicional.

A pesar de lo señalado en las páginas anteriores, los países que concentran la producción de drogas sicotrópicas, no sólo se ven afectados por la agudización de viejos conflictos entre el centro estatalizado y los hinterlands tradicionales. El narcotráfico y la política norteamericana al respecto, también contribuyen a acelerar ciertos conflictos y dilemas al interior mismo de los centros estatales y de la sociedad "moderna" de los respectivos países.

Las presiones norteamericanas ponen a los centros estatales frente a una serie de encrucijadas. La más grave de ellas, es el conflicto entre la necesidad de mantener cierto acceso a la asistencia y la ayuda económica norteamericana, así como un clima amistoso en las negociaciones entre ambas partes en temas como la deuda, el comercio exterior o las inversiones privadas, frente a los costos que la lucha contra la droga le impone a la capacidad del Estado para controlar los espacios sociales débilmente integrados a su modus operandi. ${ }^{33}$

En los países productores de drogas, el equilibrio de las instituciones políticas centrales ha dependido de su capacidad para coexistir y tolerar el florecimiento de estas lógicas "autónomas" y de su capacidad para dejarse penetrar por ellas, a cambio de un mínimo de legitimidad frente a la sociedad constituida en sus márgenes. El Estado, en los citados países ha podido afirmarse sólo a costa de numerosos eclecticismos, en los cuales las lógicas burocrático-normativas han debido armonizarse de manera sui géneris con las de corte familísticoy patrimonialista. La presión de la lucha anti-drogas fuerza a los aparatos estatales a intentar funcionar al margen y en contra de tales prácticas consuetudinarias, las cuales favorecen el encubrimiento de actividades ilegales pero socialmente aceptables.

Al ponerse en esta campaña "normativizadora" los aparatos estatales corren el riesgo de perder su base concreta de legitimidad societal. El discurso "nómico" del poder era aceptado en la medida

[33] Ver artículo de Newsweek, op. cit.; Craig, op. cit; Craig Pyes y Laurie Becklund, "Inside Dope in E1 Salvador", The New Republic, febrero 6, 1985; John Thomas, Servicio de Cultura y Prensa de la Embajada de los Estados Unidos en Santiago de Chile, "Narcóticos en América Latina", junio 16, 1987. 
Fernando Bustamante / La política de Estados Unidos contra el .. .

que dejaba libertad de acción a amplios sectores de actividad autónoma de la sociedad. La ficción del Estado racional burocrático puede sostenerse en la medida en que éste no se tome demasiado en serio su vocación de regimentación social. Al ponerse en campaña en contra de la droga, el Estado socava este pacto tácito con las instituciones y grupos que podían coexistir con él dentro de un esquema latitudinario, y abre las puertas para una creciente hostilidad que se traduce en quiebres al interior del aparato público y en sus distintos niveles. Por otra parte, la alta vulnerabilidad de estos Estados a la presión externa y la alta dependencia de los Estados Unidos, hace imposible que puedan evitar tal enfrentamiento.

Los Estados necesitan de una base fiscal mínima y de una legitimidad suficiente frente a los sectores empresariales. Si las acciones del Estado socavan la capacidad de la economía nacional "legítima" para obtener financiamiento, puede anticiparse una doble crisis: fiscal y de confianza. De este modo, los Estados de los países narco-productores se ven obligados a navegar entre el temor a la sanción punitiva de los Estados Unidos y la resistencia societal interna que, en cualquier caso, tensiona la capacidad estatal para retener el control soberano sobre población y territorio.

El conflicto anterior se traslada al seno de la formación políticoestatal según los alineamientos preferenciales de ciertos actores "centrales". Normalmente aquellos grupos más ligados al mercado internacional, a la finanza y a las ramas tecno-buroçáticas que hacen de inter-fase con el mundo exterior, serán mucho más sensibles a la necesidad de sumar activamente al país a la cruzada anti-drogas, de acuerdo a las modalidades dictadas desde Washington.

En cambio, aquellos sectores de liderazgo político y empresarial más asociados a la mantención de un bloque "nacional" de poder, o sea preocupados con la mantención de la legitimidad y el acatamiento del Estado en su forma ecléctica, se mostrarán preocupados por los impactos desestabilizantes y "anómicos" de la campaña anti-droga. Entre estos sectores podríamos encontrar a grupos asociados a las coaliciones nacional-populistas que tanta importancia histórica han tenido en la mayoría de estos países; o los grupos que articulan la gestión cacical con los aparatos formales del Estado. La movilización legalista del poder del Estado en contra de las redes clientelares del hinterland, puede desestabilizar su función y quitarles aquellos roles en torno a los cuales habían consolidado su poder de intermediarios en la escena política. 
En cualquier caso, tal conflicto puede generar divisiones muy marcadas dentro del propio mundo oficial: un ejemplo lo hallamos en Colombia, donde la disputa en torno a la legalización de la marihuana o del tratado de extradición con los Estados Unidos, ha llegado a plantearse en el nivel constitucional. En 1986 altos personeros del Consejo de Estado y la Corte Suprema de Justicia, se pronunciaron en favor de la legalización del tráfico de drogas y en contra del citado tratado de extradición. Cabe notar que los personeros involucrados estaban lejos de estar asociados con las mafias; su preocupación consistía fundamentalmente en precautelar la viabilidad del Estado y de la administración frente a presiones externas e internas. Para estos voceros, la lucha contra la droga amenazaba socavar al Estado y coartar el eficaz ejercicio de su soberanía. Las discrepancias aludidas surgían de la ansiedad frente a la situación de un aparato público desgarrado por la presión combinada de los narcotraficantes y de la diplomacia norteamericana. ${ }^{34}$

Las tensiones sobre la integridad de las instituciones estatales se ven agravadas sin duda por la práctica estadounidense de condicionar la ayuda económica al desempeño de los países en la lucha anti-narcóticos. Normalmente las agencias norteamericanas imponen criterios muy rigurosos de lo que debe considerarse un avance satisfactorio, sin tener presente las enormes limitaciones que los gobiernos tienen en llevar adelante la represión del narcotráfico. ${ }^{35}$ De esta forma, el efecto real de las presiones norteamericanas es el de bloquear un mayor desarrollo de las capacidades estatales locales, justo en circunstancias en que éstas se ven más severamente exigidas. Con ello, la legitimidad de los sectores aliados locales se ve socavada y su eficacia reducida. Ante esto la única solución sería que Estados Unidos dejara de insistir en stándares de eficacia poco realistas y de suponer a los Estados sudamericanos una eficacia y una capacidad que están lejos de tener. Al imputar tal nivel de eficacia exagerado, los Estados Unidos no pueden explicarse los fracasos y limitaciones del programa anti-drogas sino suponiendo que sus contrapartes locales son "blandas" o carecen de un verdadero compromiso con el combate anti-narcóticos. De esta manera, en muchos círculos oficiales de los Estados Unidos cunde la sensación de que el conjunto de las instituciones latinoamericanas son tolerantes o carecen de buena

[34]Ver, artículo sobre el tema en Mensaje Iberoamericano, op. cit

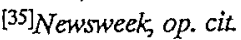


Fernando Bustamante / La política de Estados Unidos contra el ...

voluntad, lo cual aumenta, a su vez, la hostilidad hacia quienes deberían ver los aliados locales de la política anti-droga de los Estados Unidos. ${ }^{36}$

Desde el punto de vista de los gobiernos latinoamericanos se produce malestar por lo que parece una duplicidad norteamericana: por un lado la retórica en Washington enfatiza la prioridad y la importancia de la lucha anti-drogas; pero la práctica consiste en socavar y hostilizar a quienes se les da la tarea de ser la primera línea de choque en tal "cruzada". Un ejemplo claro de esto fue la propuesta de la "Ley Hawkin" que en 1985 intentó prohibir la entrega de 50 millones de dólares a Bolivia, para castigar a dicho país por su incapacidad en erradicar las plantaciones de coca. Dichos fondos buscaban precisamente sostener al fisco boliviano en la esperanza de reducir el incentivo para tolerar el narcotráfico como único medio de sostener la arruinada economía boliviana. La carencia de fuentes financieras alternativas hacía mucho más plausible la posición de quienes sostenían que el "narco-dólar" era el único recurso que le quedaba a Bolivia para evitar la bancarrota nacional. ${ }^{37}$

Este caso ilustra el dilema de una política de sanciones negativas que elimina los incentivos a la cooperación, sin eliminar, por otra parte, las ventajas de la no-cooperación, esto es: los ingresos del narcotráfico, los cuales, son con frecuencia lo suficientemente cuantiosos como para compensar ampliamente las pérdidas en ayuda que las sanciones pueden traer aparejadas. Por otra parte, una escalada de sanciones que lleva a estar a un nivel capaz de afectar al Estado latinoamericano-ej.: el boicot al turismo mexicano y el hostigamiento aduanero que se implementó para presionar la solución del caso del agente Camarena de la OEA- más allá del nivel de las ventajas de la no cooperación, arriesga comprometer otros intereses estadounidenses. Es preciso recordar que la lucha anti-narcóticos no es el único tema en el cual Washington requiere de la cooperación de sus socios hemisféricos. Una presión demasiado brutal en torno a la droga, puede tal vez lograr su efecto punitivo neto; pero puede también socavar la voluntad local para ayudar a los Estados Unidos en otras áreas de la relación bilateral.

[36] Hostilidad que es muy palpable, por ejemplo en la actitud de la Senadora Paula Hawkings en la Audiencia citada: marzo 13, 1985; ver actas de la sesión; también ver palabras del Senador Grassley.

${ }^{[37}$ En la citada audiencia tales reflexiones fueron explicitadas por el Senador Metzenbaum, para fundamentar su oposición a "castigar" a Bolivia. 
Esto plantea los límites de una política norteamericana basada en incentivos negativos para inducir a la cooperación de los gobiernos locales. Y esto ha sido expresado por el Senador Metzembaum, quien señala que el dilema de los Estados Unidos consiste en que si se rompen relaciones o se castiga a las naciones que no brindan plena cooperación a los esfuerzos anti-droga pero que son amigables en otros campos y que también son anti-soviéticas, se corre el riesgo de que ellas "deserten" del bloque pro-occidental o que retiren su contribución a la política de contención dentro del marco del conflicto Este-Oeste. $^{38}$

De esta forma, la altísima prioridad que se concede al conflicto bipolar, entraba e inhibe la capacidad norteamericana para castigar a sus vecinos poco cooperadores. La misma lógica coarta los esfuerzos de Washington para inducir a Sudráfrica a poner fin al apartheid, para promover la democratización en países con gobiernos militares autoritarios o para distanciarse de ciertos países del Medio Oriente que poco tienen de parecido a las democracias occidentales.

\section{Reflexiones finales}

De las páginas anteriores se desprende que, en buena medida, la política norteamericana de lucha contra el narcotráfico en Latinoamérica se halla traspasada por un conjunto de malentendidos básicos. Estos últimos arrancan de una básica incomunicación entre las formas de construir la realidad de tal fenómeno por parte de ambos mundos. Para los norteamericanos, la cuestión de la droga es un problema que se sitúa en el ámbito de lo delictual y de lo epidemiológico, y por tanto se halla anclado en una topografía conceptual propia de una cierta modernidad segura de sí misma y centrada en una preocupación con la pureza y buena administración del cuerpo. Sin duda que un autor como Foucault no tendría dificultades en reconocer los tópicos de la obsesión retórica del gobierno y la opinión pública estadounidense con el citado problema. Al margen de la objetividad de la amenaza que la drogadicción representa para la sociedad, ella es una amenaza contra los focos de la auto-imagen y la identidad de una sociedad que se ve a sí misma a través de los ojos morales de un calvinismo purista y de un racionalismo instrumentalista, en ninguno de los cuales la "estupefacción" tiene más lugar que el [38] bid. 
Fernando Bustamante / Là política de Estados Unidos contra e1 ...

de "lo otro." que confunde y difumina las nítidas fronteras del hacer regulado por una racionalidad medio-fines.

Desde el punto de vista latinoamericano, tal perspectiva es problemática. Sin duda que existen grupos y élites que aceptan y: se incluyen en tal perspectiva general; pero vastos espacios sociales y. culturales viven la droga desde orillas mentales por completo distintas. La droga no es consumo, sino producto; no es factor de disolución, sino de identidad; no es profanación, sino instrumento de lo sagrado; no es juzgada por su utilidad, sino por su participación en la vida inmanente de los seres; no es germen amenazante, sino alimento; $y$ no es producto refinado, cristal industrializado, bien final, sino extracto de la naturaleza: hoja, hierba, flor que vive en los campos de los cuales vive el hombre común.

Las luchas en torno a la droga no son en la vida del hinterland latinoamericano combates policíacos llevados en los márgenes oscuros de la sociedad, sino que parte de una lucha central, vasta y antigua que contrapone al "pueblo" y a la "naturaleza", a lo "autóctono" y "próximo", contra la presión impersonalizante de un Estado normativo/racional, lejano y ajeno. El Estado de los "doctores" y "funcionarios" que para el campesino o el provinciano son fuerzas extranjeras, fastidios permanentes e incomprensibles, una amenaza para su autonomía basada en reglas sociales rigurosas: la amistad, la familia real o ritual, la reciprocidad del favor, el honor y el patriarcalismo extenso.

La lucha contra la coca o la marihuana parece así otro avatar de las duras luchas seculares entre el Estado de los burócratas y el mundo de los habitantes "reales": lucha que halla su eco en las de los encomenderos contrá el Consejo de Indias y su fastidiosa pero lúcida reglamentación; en la de los hacendados contra los gobiernos capitalinos; en la de los comuneros zapatistas contra el sistema "científico" del porfirismo y sus secuelas; en las rebeliones milenaristas del nordeste brasilero contra la república del "orden y el progreso"; en los motines de los indios ecuatorianos contra los intentos de los servicios médicos del Estado para establecerse en su seno; etc.

En todo caso, la lucha en Latinoamérica gira en torno al problema secular del acatamiento de la modernidad por parte de los estratos plebeyos y de su tejido social familístico, más que en torno al problema de la internalización individual y moral de una cierta ética del cuerpo como en los Estados Unidos, y esta diferencia marca el abismo entre los enfoques y las políticas que se ven posibles y eficaces a ambos lados de la brecha. 
Las políticas que impulsan los norteamericanos tienen como consecuencia no anticipada, la de someter a presiones adicionales a los débiles sistemas estatal-institucionales de los países productores y amenazar las posiciones de los portadores de la modernidad política, que aparecen como cada vez más extraños a la sociedad que intentan disciplinar haciéndose eco de la política de Washington. Asimismo, esta agudización del conflicto entre instituciones y redes clientelístico-familísticas activa y potencia la movilización política de los grupos ligados a la droga, induciéndolas a intentar la contra-penetración en las estructuras estatales. En distintos países esto se implementa de diferentes maneras. En Colombia a través de ciertas estructuras regionales y cacicales y de ambos grandes partidos históricos, así como de ciertos mandos guerrilleros del M-19 y el FARC.

En Ecuador se asiste a la penetración de redes "narco" en los partidos empresariales como el social-cristianismo y en los movimientos populistas, especialmente el CFP (Concentración de Fuerzas Populares); en Perú en la política local de las áreas productoras, y en Bolivia a través de las Fuerzas Armadas y la fuerte presencia del empresariado agrícola cruceño y del Beni en la Acción Democrática Nacionalista del General Banzer. En todos estos casos, los intereses "narco" revisten la forma de resistencia social pluriclasista en contra del esfuerzo represivo y legalista del Estado central y sus agentes burocráticos.

La política estadounidense amenaza pues, de distintas maneras, el equilibrio tradicional de los países andinos y las formas seculares de convivencia semi-pacífica entre instituciones estatales y "pueblo" (en el sentido etnocultural que el término alemán: "volk" captura con especial precisión). Esto contribuye a debilitar a los Estados tanto frente a actores externos como internos y a elevar las demandas sobre sus recursos de todo tipo. De esta forma, la política norteamericana de poner el acento en la destrucción de las fuentes de abastecimiento de la droga -política que es racional desde un punto de vista tecnológico y operacional (el consumo y el tráfico son móviles y "capilares", el cultivo es fijo e inmueble en el corto plazo, era más fácilmente detectable y destructible)- genera una vasta red de consecuencias socio-políticas no anticipadas y, en algunos casos, puede contribuir a socavar los propios objetivos del programa anti-estupefacientes.

Ante esto, cabe preguntarse por las posibles alternativas en la actual política. En primer lugar, es preciso reconocer que las políticas 
Fernando Bustamante / La política de Estados Unidos contra e1 ...

estatales se formulan sobre la base de consensos relativamente profundos respecto a la naturaleza de lo real y de los posibles que ese real define. En el caso de la lucha anti-narcóticos, la formulación de una política que tenga en cuenta las construcciones de la realidad propias de las distintas sociedades involucradas, tropieza con el hecho de que el abismo perceptual y categorial entre ellas es de grandes proporciones. Es más, no sólo existen estas brechas, sino que su cierre no se presenta a los actores como una necesidad o una tarea previa -en un sentido lógico- a la política. La premura por "hacer algo" se antepone y avasalla la menor "eficaz" actividad de establecer una estructura comunicacional entre mundos de representaciones colectivas tan marcadamente distantes. La situación está definida de manera tal que la paciente racionalidad dialógica que permitiría establecer una inter-subjetividad compartida y compartible, parece imposible, al menos por ahora.

Sobre la base de esta constatación inicial "pesimista", es preciso preguntarse qué es posible pedir al otro.

Una reflexión considerada permite esbozar los marcos de esfuerzos posibles que podrían aliviar la aspereza de la yuxtaposición entre la premura norteamericana, la sorda resistencia de las sociedades locales y el desgarramiento de las élites estatales latinoamericanas.

En primer término, parece posible pensar que los latinoamericanos deben hacer valer con plena legitimidad su percepción más compleja y matizada del problema de la droga. Si bien no resulta conducente oponerse frontalmente a las políticas estadounidenses, no puede desestimarse el efecto de una consistente articulación discursiva de la rica y complicada realidad local. Esto puede permitir ejercer una cierta selectividad frente a las propuestas de intervención anti-narcóticos de los Estados Unidos. Debe apoyarse y proponerse aquellas acciones que sean relativamente menos disruptivas de los derechos de la sociedad tradicional para vivir y reproducirse de acuerdo a sus prioridades endógenas. Debe pues evitarse que la guerra contra la industria del narcotráfico sea el vehículo para desatar una guerra anti-cultural, autoritariamente normativizadora y avasallante de lo vernáculo. Debe por otro lado, evaluar y sopesar cuidadosamente las capacidades reales que tiene el Estado-nacional para luchas contra el narcotráfico sin desbordar sus propias capacidades y cohesión interna, o sin desatar procesos de involución y desgarramiento internos de azaroso manejo. 
En este sentido, tales costos societales, burocráticos, y políticos deben ser claramente explicitados frente a Estados Unidos. Estos últimos no pueden pretender que los Estados nacionales paguen ellos solos o preferencialmente los costos de una lucha cuyo beneficiario principal son todavía los propios Estados Unidos. Los países latinoamericanos deben insistir que la cooperación norteamericana debe revestir montos y modalidades compatibles y conmensurados con: i) el beneficio que los propios Estados Unidos esperan derivar de la lucha anti-narcotráfico; ii) los costos que los países puedan pagar sin comprometer otros valores importantes para ellos, aunque tal vez no para Washington.

En otras palabras, los Estados Unidos deben poner su dinero al nivel de su retórica.

Desde la perspectiva norteamericana parece claramente desaconsejable insistir en una política de sanciones y castigos que no hace sino socavar aún más la voluntad y la capacidad de los Estados para controlar la producción y comercio de estupefacientes. Más racional parecería una política de incentivos y de apoyo, que aunque en el corto plazo puede tener menos efecto, sienta las bases para un acercamiento de estrategias y perspectivas más durable. Una política de presiones como las usadas con México, corre el riesgo de presentar a los narcotraficantes como los depositarios de la soberanía nacional y símbolos de la resistencia anti-imperialista, y al gobierno legal como un mero agente servil de los dictados de una potencia extranjera. Tal situación no puede conducir a la formación de un consenso nacional anti-drogas.

Los Estados Unidos podrían enfatizar sus programas internos destinados a combatir la drogadicción y el tráfico de narcóticos. $\mathrm{Ha}$ sido una queja justificada el que Washington ha hecho muy poco para controlar la demanda interna, la que en definitiva mueve el negocio de los narcóticos. En los últimos dos años se isinúan avances en ese sentido, lo que hace pensar que no es utópico creer que los Estados Unidos lleguen a convencerse de la importancia de un enfoque que dé su debido lugar al factor doméstico. Aparte de las ventajas sustantivas de tal orientación, ello permitiría a los norteamericanos demostrar seriedad y buena fe en sus negociaciones con sus vecinos latinoamericanos. Un esfuerzo interno más vigoroso permitiría a Estados Unidos recabar con mayor autoridad, esfuerzo y sacrificios comparables de los países latinoamericanos. 
Fernando Bustamante / La política de Estados Unidos contra el . . .

Parece importante, por último, evitar la militarización de la lucha anti-drogas. Las propias Fuerzas Armadas estadounidenses y sus colegas latinas, parecen muy poco entusiastas frente a las presiones civiles que buscan entregarles un rol crucial en tales tareas. Los militares temen -con justa razón- que su involucramiento masivo en la lucha anti-narcotráfico los saque del ámbito de sus prioridades profesionales, los someta a tensiones políticas que están mal preparadas para soportar su detrimento y los ponga en peligro de corrupción y desintegración moral.

Asimismo, el enfoque militarizado de la lucha anti-droga arriesga en convertir un problema sico-social en una "guerra" de una parte de la sociedad contra otra, o de una potencia extranjera contra el "pueblo" de ciertas áreas interiores de Latinoamérica. Si se desea prevenir que la lucha anti-droga degenere en una cruzada bélica con sus secuelas desintegrativas y sus costos sociales, humanos y culturales, debe buscar recentrarse la cuestión entendiendo que el narcotráfico, la producción y el consumo de estupefacientes son facetas cada una muy distinta donde lo legal, lo sicológico, lo político, lo cultural y lo económico se entrecruzan de manera sui géneris y con distinto peso específico a cada nivel. Un enfoque más político de la cuestión de la droga, permitiría un enfrentamiento más concreto, humano y comunicacionalmente sano, que el desafortunado recurso a la lógica de la guerra, sea ésta con cierto éxito como en Sonora, sea sin ninguno como en el Beni o en el Chaparé.

Como orientación general parece necesario pues recentrar el problema del narcotráfico como un fenómeno que exige una sofisticada resolución que parte por una abierta y libre discusión política de los objetivos que cada sociedad debe plantearse frente a la realidad de la droga, y de soluciones que asuman la perspectiva de todos los actores, de una manera comprensiva y "desde adentro", evitando las fáciles figuras de la conspiración, la guerra, la epidemia, las cuales presentan de una manera fantasmagórica realidades mucho más diferenciadas y concretas. 